\title{
The Effect of Treatment of Twin-Twin Transfusion Syndrome on the Diagnosis-to-Delivery Interval
}

\author{
Daniel W. Skupski, Keerti Gurushanthaiah, and Stephen Chasen \\ New York Presbyterian Hospital-Weill Cornell Center, USA
}

N randomised controlled trials of treatment of twin-to-twin transfusion syndrome (TTTS) exist. Since severely preterm neonatal survival has increased over time, survival as an outcome measure is confounded by improvements in neonatal care. The diagnosis-to-delivery interval is a measure of success of treatment independent of improvements in neonatal care. We wished to evaluate whether treatment of TTTS is associated with a lengthening of the diagnosis-to-delivery interval. MEDLINE search was performed supplemented by careful reference review. All TTTS series were included where the following information on each patient was available: survival, fetal demise, gestational age at diagnosis and diagnosis-todelivery interval in days. Inclusion criteria: gestational age at diagnosis < 29 weeks and diagnosis by ultrasound in the absence of maternal symptoms. Cases undergoing multiple types of treatment were excluded. Eight publications met inclusion criteria and included the following cases: controls ( $n$ $=16)$, amnioreduction ( $n=61)$, septostomy $(n=12)$, and fetoscopic laser occlusion of chorioangiopagus vessels $(n=51)$. There was no difference in the diagnosis-to-delivery interval, overall survival, at least one survivor, or number of fetal deaths between the four groups. Logistic regression using at least one survivor as the dependent variable revealed a positive association with gestational age at diagnosis and with diagnosis-to-delivery interval, a negative correlation with fetal death, and no correlation with treatment group. We conclude that there is no difference in diagnosis-to-delivery interval or survival for any treatment for TTTS compared to expectant management. The lack of significance appears to be due to small sample sizes.

The prenatal diagnosis of twin-twin transfusion syndrome (TTTS) has been possible for nearly 20 years (Wittmann et al., 1981). Several treatments have been developed during this time, most of which have been evaluated in large prospective case series (DeLia et al., 1995; Saade et al., 1998; Saunders et al., 1992). Because of the high perinatal mortality associated with TTTS, the most common outcome measure in these series has been survival. Recently, other outcome measures have been investigated, including neurologic handicap in survivors (Reisner et al., 1993), the rate of survival of at least one twin (Ville et al., 1995) and the effect of treatment on the diagnosis-to-delivery interval (Hecher et al., 1999).

Although treatments have been evaluated for more than 15 years (Feingold et al., 1986), there are no published randomised controlled trials (RCT) of treatment for TTTS (Skupski, 2000). During this time period, each successive published series of survival of neonates born after the prenatal diagnosis of TTTS has shown improved survival (Dennis \& Winkler, 1997; Saade et al., 1998; Urig et al., 1990; Ville et al., 1995; Ville et al., 1998). During this same time period, there has been marked improvement in survival of severely preterm singleton and twin neonates (Skupski, 1998). Thus, it is difficult to separate the effect of TTTS treatments from the effect of increased neonatal survival over time (Skupski, 1998). This difficulty, combined with the lack of RCT's argues for attempts to evaluate current therapies with outcome measures other than survival. Specifically, outcome measures that are independent of the improvements in neonatal care should be investigated.

One possible benefit of therapy that would be expected to improve survival independent of improvements in neonatal care is a lengthening of the diagnosis-to-delivery interval. A recent study showed lengthening of the diagnosis-to-delivery interval when fetoscopic laser occlusion of chorioangiopagous vessels (FLOC) was used compared to amniotic fluid volume reduction (amnioreduction) (Hecher et al., 1999). Further support for this concept would be helpful. A question that remains is if any current therapy increases the diagnosis-to-delivery interval compared to expectant management. The purpose of this study was to evaluate the effect of current therapies for TTTS on the diagnosis-to-delivery interval and to compare these to expectant management.

\section{Materials and Method}

A MEDLINE search was performed to identify all published series of cases of TTTS using the search terms "twin-to-twin transfusion syndrome", "twin transfusion", "twin oligohydramnios polyhydramnios sequence" and "fetofetal transfusion." Additional studies were obtained by careful review of the reference lists. Series of TTTS were included in the current study if information on each patient was reported or could be obtained by contacting the author, including survival, timing of demise (fetal versus neonatal), gestational age at diagnosis and diagnosis-

Address for correspondence: Daniel W. Skupski MD, The New York Hospital Medical Center of Queens, Dept. of Ob/Gyn, \# 4 South, 56-45 Main Street, Flushing, NY 11355, USA. Email: dwskupsk@med.cornell.edu 
to-delivery interval in days. Cases were included only if the diagnosis was made by ultrasound prior to delivery. Exclusion criteria were $>29$ weeks of gestation, multiple types of treatment, and maternal symptoms of preterm labor or respiratory embarrassment at the time of diagnosis. The main outcome measure was diagnosis-to-delivery interval in days. Secondary outcome measures included total survival, at least one survivor per pregnancy and rate of fetal deaths. FLOC data from DeLia et al. (1995) were supplemented with recent cases managed by that author and posted on a website (http://www.tttsfoundation. org/handout.htm). The FLOC group included a procedure-to-delivery interval because the diagnosis-to-delivery interval was not available. Data were evaluated by Chisquare, Kruskal-Wallis ANOVA, logistic regression and Mann-Whitney-Wilcoxon rank sum testing where appropriate. Significance was defined as $p<0.05$.

\section{Results}

There were eight publications that met entry criteria (DeLia et al., 1995; Dennis \& Winkler, 1997; Dickinson, 1995; Elliott et al., 1991; Gonsoulin et al., 1990; Pinette et al., 1993; Saade et al., 1998; Urig et al., 1990). These studies included cases in four treatment categories: expectant management (controls) $(n=16)$, amnioreduction $(n=$ $61)$, septostomy $(n=12)$ and fetoscopic laser occlusion of chorioangiopagus vessels (FLOC) $(n=51)$. Figure 1 shows the distribution of diagnosis-to-delivery interval data for the four treatment groups.

Kruskal-Wallis one-way ANOVA showed no difference in diagnosis-to-delivery interval between the four groups $(p=$ $0.08)$. The median and range of diagnosis-to-delivery interval in days for the four treatment groups are shown in Figure 1. There was no difference in total survival, at least one survivor or rate of fetal deaths between the four treatment groups (chi-square analysis). The survival data for each of the

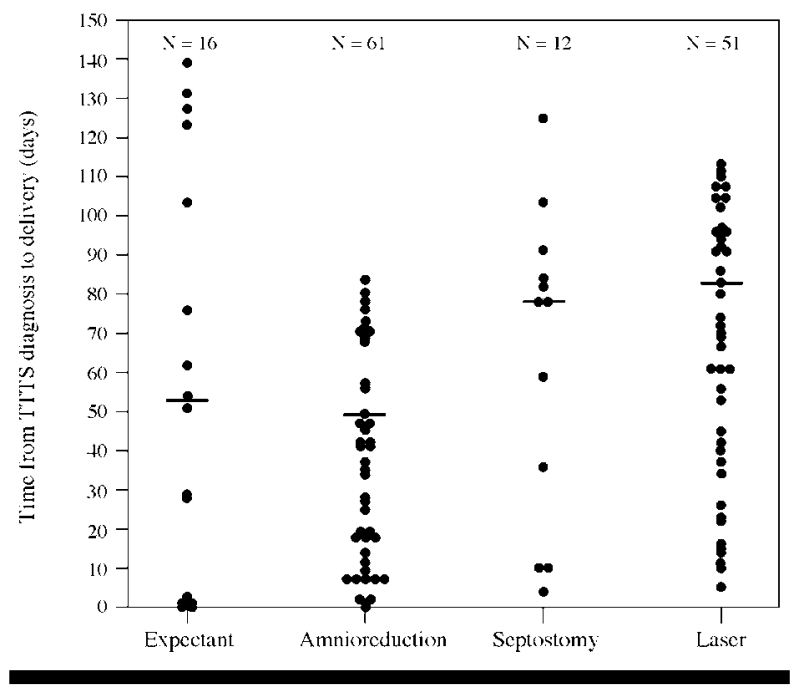

Figure 1

Diagnosis-to-delivery interval data in twin-twin transfusion syndrome pregnancies (according to treatment group). TTTS $=$ Twin-twin transfusion syndrome. four treatment groups is shown in Figure 2. Logistic regression using at least one survivor as the dependent variable revealed a positive association with gestational age (GA) at diagnosis (later GA at diagnosis = increased chance of at least one survivor) ( $p=0.02)$ and with diagnosis-to-delivery interval (longer interval $=$ increased chance of at least one survivor) $(p=0.03)$, a negative correlation with fetal death (any fetal death $=$ decreased chance of at least one survivor) $(p=0.05)$, and no correlation with treatment group. Table 1 compares survival rates for the current study to those of recent case series, showing no marked differences.

Power analysis was performed to determine the sample size required to detect a significant difference in total survival and in at least one survivor between the amnioreduction and FLOC groups based on the proportion of survivors in these two groups in the current study. Using a power of $80 \%$ and a significance level of $p=0.05$, we found that 1137 patients would be needed in each group to find a significant difference in total survival, and 236 patients in each group to find a difference in at least one survivor.

\section{$\overline{\text { Discussion }}$}

The finding of no difference in the diagnosis-to-delivery interval between the four treatment groups should not be surprising, because only one study has attempted to perform such a comparison, and this was between two groups, amnioreduction and FLOC (Hecher et al., 1999). The current study does not support the study of Hecher et al. (1999), who found that FLOC showed a significant lengthening of the diagnosis-to-delivery interval. The only way to resolve this issue is with randomised controlled trials. There are two randomised controlled trials of treatment for TTTS currently underway, and the data presented argue for the support of these trials. We would encourage that all patients diagnosed with TTTS be encouraged to participate in these trials.

There was no difference between the four treatment groups in the occurrence of at least one survivor, which has

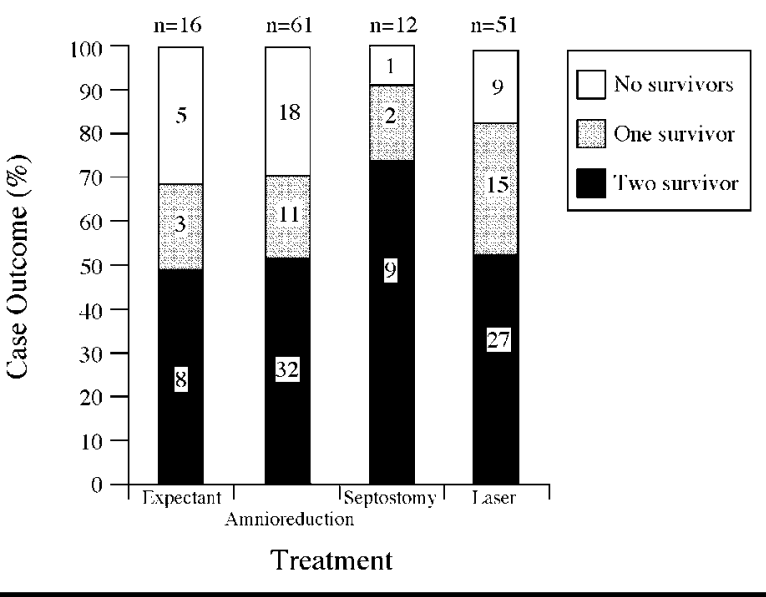

Figure 2

Survival data in twin-twin transfusion syndrome pregnancies (based on treatment group). 
Table 1

Proportions of Surviving Neonates after Treatment for Twin-twin Transfusion Syndrome: Literature Review

\begin{tabular}{|c|c|c|c|c|c|c|c|}
\hline First author & Year & Treatment & $N$ & $\begin{array}{c}\text { No survivors } \\
(\%)\end{array}$ & $\begin{array}{c}\geq 1 \text { survivor } \\
(\%)\end{array}$ & $\begin{array}{c}2 \text { survivors } \\
(\%)\end{array}$ & $\begin{array}{c}\text { Total survival } \\
(\%)\end{array}$ \\
\hline Ville & 1995 & Laser & 45 & 29 & 71 & 36 & 53 \\
\hline DeLia & 1995 & Laser & 26 & 31 & 69 & 35 & 53 \\
\hline Saade & 1998 & Septostomy & 12 & 8 & 92 & 75 & 83 \\
\hline Ville & 1998 & Laser & 132 & 27 & 73 & 36 & 55 \\
\hline Mari & 1998 & Amnio* & 175 & NA & 75 & 55 & 66 \\
\hline Hecher & 1999 & Laser & 116 & 21 & 79 & 42 & 61 \\
\hline \multirow[t]{3}{*}{ Current study } & 1986-1998 & Control & 16 & 31 & 69 & 50 & 59 \\
\hline & & Amnio* & 61 & 30 & 70 & 52 & 61 \\
\hline & & Laser & 51 & 18 & 82 & 53 & 67 \\
\hline
\end{tabular}

Note: *Amnio = amnioreduction

$\mathrm{NA}=$ not available

been suggested to be improved with the use of FLOC (Hecher et al., 1999; Ville et al., 1998; Ville et al., 1995). With the exception of Hecher et al. (1999) all previous reports have been series of cases managed with a single treatment, and thus the comparison could not be made. When tabulating recent experience with several treatments, there appears to be no difference in the occurrence of at least one survivor between amnioreduction, septostomy and FLOC (Table 1) (Skupski, 2000). This study shows the first comparative evidence of no benefit of any therapy in the outcome measure of at least one survivor.

Similar to the outcome of at least one survivor, fetal deaths were not different between the four groups. It has been suggested that the use of FLOC may be associated with an increase in at least one survivor while also increasing the chance of fetal death of the donor (Ville et al., 1995). The current study — the first comparative study does not support this notion, nor the notion that any therapy has a similar association.

There were several expected findings by logistic regression. The gestational age at diagnosis was positively correlated with at least one survivor. In other words, the later the gestational age at diagnosis, the more likely there was to be at least one survivor. A positive correlation was also seen for the diagnosis-to-delivery interval. In other words, the longer the interval, the more likely there was to be at least one survivor. Not surprisingly, a negative correlation was seen with fetal death and at least one survivor. The expected findings support the veracity of the data. Importantly, there was no correlation with any treatment group and at least one survivor. The finding of no correlation of any treatment with improved survival again highlights the need for randomised controlled trials to address this issue.

Although it may not be appropriate to perform an individual analysis, when the data in this study are used to compare FLOC therapy to amnioreduction by Wilcoxon rank sum testing, FLOC showed a significantly longer diagnosis-to-delivery interval (median 75 vs. 56 days) ( $p=$ $0.01)$. In addition, the ANOVA results for all four groups showed a trend toward significance in the same direction $(p$
$=0.08)$. These findings are evidence that the sample sizes were too small to make firm conclusions.

This study is limited due to its retrospective nature and the method of acquiring cases. Since those patients with preterm labor or maternal respiratory embarrassment at the time of diagnosis were excluded, and only those with the diagnosis-to-delivery interval available in number of days were included, this meant that some cases were included and excluded from the same publication. This necessary selective process introduced bias (Schulz et al., 1995). It was important to exclude symptomatic cases due to the certainty of treatment failure in gaining any time between diagnosis and delivery in previous publications (Mahoney et al., 1990; Urig et al., 1990). Another limitation is the lack of concordance in diagnostic criteria across the eight studies. Only one study included a defined level of oligohydramnios and polyhydramnios in addition to prospective ultrasound determination of monochorionicity (same gender, single placenta, thin intertwin membrane) (Pinette et al., 1993), and only four of the studies confirmed monochorionicity by placental pathologic examination (DeLia et al., 1995; Dickinson, 1995; Pinette et al., 1993; Urig et al., 1990). Criteria for prenatal diagnosis are now available and should be applied uniformly (Skupski, 1999). This should decrease the problem of widely differing survival rates due to the inclusion of cases that are not truly TTTS.

In summary, there is no difference in diagnosis-to-delivery interval or survival for any treatment for TTTS compared to expectant management. The lack of significance appears to be due to small numbers of cases in each group.

\section{References}

De Lia, J., Kuhlmann, R. S., Harstad, T. W., \& Cruikshank, D. P. (1995). Fetoscopic laser ablation of placental vessels in severe previable twin-twin transfusion syndrome. American Journal of Obstetrics and Gynecology, 172, 1202-1211.

Dennis, L. G., \& Winkler, C. L. (1997). Twin-to-twin transfusion syndrome: Aggressive therapeutic amniocentesis. American Journal of Obstetrics and Gynecology, 177, 342-349. 
Dickinson, J. E. (1995). Severe twin-twin transfusion syndrome: Current management concepts. Australian and New Zealand Journal of Obstetrics and Gynaecology, 35, 16-21.

Elliott, J. P., Urig, M. A., \& Clewell, W. H. (1991). Aggressive therapeutic amniocentesis for treatment of twin-twin syndrome. Obstetrics and Gynecology, 77, 537-540.

Fanaroff, A. A., Wright, L. L., Stevenson, D. K., Shankaran, S., Donovan, E. F., Ehrenkranz, R. A., Younes, N., et al. (1995). Very-low-birth-weight outcomes of the National Institute of Child Health and Human Development Neonatal Research Network, May 1991 through December 1992. American Journal of Obstetrics and Gynecology, 173, 1423-1431.

Feingold, M., Cetrulo, C. L., Newton, E. R., Weiss, J., Shakr, C., \& Shmoys, S. (1986). Serial amniocenteses in the treatment of twin to twin transfusion complicated with acute polyhydramnios. Acta Geneticae Medicae et Gemellologiae, 35, 107-113.

Gonsoulin, W., Moise, K. J., Jr., Kirshon, B., Cotton, D. B., Wheeler, J. M., \& Carpenter, R. J. (1990). Outcome of twintwin transfusion diagnosed before 28 weeks of gestation. Obstetrics and Gynecology, 75, 214-216.

Hecher, K., Plath, H., Bregenzer, T., Hansmann, M., \& Hackeleor, B. J. (1999). Endoscopic laser surgery versus serial amniocenteses in the treatment of severe twin-twin transfusion syndrome. American Journal of Obstetrics and Gynecology, 180, 717-724.

Mahoney, B. S., Petty, C. N., Nyberg, D. A., Luthy, D. A., Hickok, D. E., \& Hirsch, J. H. (1990). The "stuck twin" phenomenon: Ultrasonographic findings, pregnancy outcome, and management with serial amniocenteses. American Journal of Obstetrics and Gynecology, 163, 1513-1522.

Pinette, M. G., Yuqun, P., Pinette, S. G., \& Stubblefield, P. G. (1993). Treatment of twin-twin transfusion syndrome. Obstetrics and Gynecology, 82, 841-846.

Reisner, D. P., Mahoney, B. S., Petty, C. N., Nyberg, D. A., Porter, T. F., Zingheim, R. W., Williams, M. A., \& Luthy, D. A. (1993). Stuck twin syndrome: Outcome in thirty-seven consecutive cases. American Journal of Obstetrics and Gynecology, 169, 991-995.
Saade, G. R., Belfort, M. A., Berry, D. L., Bui, T. H., Montgomery, L. D., Johnson, A., O’Day, M., Olson, G. L., Lindholm, H., Garoff, L., \& Moise, K. J. (1998). Amniotic septostomy for the treatment of twin oligohydramnios-polyhydramnios sequence. Fetal Diagnosis and Therapy, 13, 86-93.

Saunders, N. J., Snijders, R. J. M., \& Nicolaides, K. H. (1992). Therapeutic amniocentesis in twin-twin transfusion syndrome appearing in the second trimester of pregnancy. American Journal of Obstetrics and Gynecology, 166, 820-824.

Schulz, K., Chalmers, I., Hayes, R. J., \& Altman, D. G. (1995). Empirical evidence of bias. Dimensions of methodological quality associated with estimates of treatment effects in controlled trials. JAMA, 273, 408-412.

Skupski, D. W. (1998). Changes in survival of preterm singletons versus twins delivered after twin-twin transfusion syndrome over the calendar years 1970-1994. Fetal Diagnosis and Therapy, 13, 334-338.

Skupski, D. W. (1999). Current perspectives on twin-to-twin transfusion syndrome. In F. A. Chervenak \& A. Kurjak (Eds.), Fetal medicine: The clinical care of the fetus as a patient (pp. 205-210). Carnforth, Lancaster, UK: Parthenon Publishing Group, Ltd.

Skupski, D. W. (2000). Twin-to-twin transfusion syndrome: Do we really understand it? Frontiers in Fetal Health, 2, 12-17.

Urig, M. A., Clewell, W. H., \& Elliott, J. P. (1990). Twin-twin transfusion syndrome. American Journal of Obstetrics and Gynecology, 163, 1522-1526.

Ville, Y., Hyett, J., Hecher, K., \& Nicolaides, K. (1995). Preliminary experience with endoscopic laser surgery for severe twin-twin transfusion syndrome. New England Journal of Medicine, 332, 224-227.

Ville, Y., Hecher, K., Gagnon, A., Sebire, N., Hyett, J., \& Nicolaides, K. (1998). Endoscopic laser coagulation in the management of severe twin-to-twin transfusion syndrome. British Journal of Obstetrics and Gynaecology, 105, 446-453.

Wittmann, B. K., Baldwin, V. J., \& Nichol, B. (1981). Antenatal diagnosis of twin transfusion syndrome by ultrasound. Obstetrics and Gynecology, 58, 123-127. 